\title{
Die Veröffentlichung von Schiedssprüchen als Beitrag zur Normbildung
}

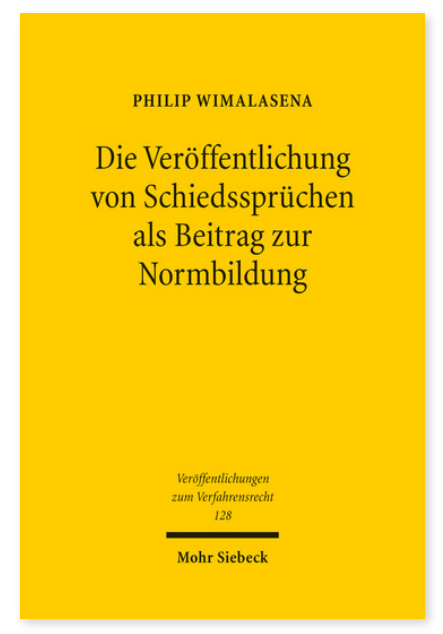

2016. XVII, 360 Seiten. VVerfR 128

ISBN 978-3-16-154640-2

DOI 10.1628/978-3-16-154640-2

eBook PDF 94,00€

ISBN 978-3-16-154326-5

fadengeheftete Broschur 94,00€
Handelsschiedsgerichte nehmen im globalen Wirtschaftsverkehr mittlerweile eine bedeutende Stellung ein. Ihr anhaltender Erfolg hat jedoch einen Preis. Anders als das durch den Öffentlichkeitsgrundsatz geprägte staatliche Zivilverfahren finden Handelsschiedsverfahren in aller Regel außerhalb der Öffentlichkeit statt, ihre Entscheidungen werden nur selten einmal öffentlich bekannt. Eine diskursive, insbesondere eine richterrechtliche Fortbildung des Rechts wird auf diese Weise weitgehend verhindert. Daraus entstehen Nachteile nicht nur für die Verfahrensbeteiligten, sondern auch für den Normbildungsprozess insgesamt. Philip Wimalasena wirbt vor diesem Hintergrund für eine größere

Entscheidungstransparenz in der Handelsschiedsgerichtsbarkeit, die vor allem durch die systematische Veröffentlichung von Schiedssprüchen verwirklicht werden soll. Er analysiert die strukturellen Voraussetzungen einer solchen allgemeinen Veröffentlichungspraxis und plädiert im Ergebnis für eine anonymisierte Veröffentlichung schiedsrichterlicher Entscheidungen.

Die Arbeit wurde mit dem Förderpreis der Deutschen Institution für Schiedsgerichtsbarkeit (DIS) e.V. 2015/2016 ausgezeichnet.

Philip Wimalasena Geboren 1983; Studium der Rechtswissenschaften in Bonn, Frankfurt am Main und Lyon; Referendariat am Kammergericht; 2015 Promotion; seit 2014 Rechtsanwalt im Bereich Prozessführung und Schiedsverfahren; derzeit Graduiertenstudium (LL.M.) an der University of Cambridge.
Jetzt bestellen:

https://mohrsiebeck.com/buch/die-veroeffentlichung-von-schiedsspruechen-als-beitrag-zur-normbildung-9783161546402?

no_cache=1

order@mohrsiebeck.com

Telefon: +49 (0)7071-923-17

Telefax: +49 (0)7071-51104 